\title{
O cotidiano dos super-heróis e protagonistas de histórias em quadrinhos em tempos de pandemia: representação social entre o mundo da ficção e o mundo real
}

\author{
Comic books superheroes and main characters' daily actions in \\ pandemic times: social representation between fiction and real \\ world
}

Rubem Borges Teixeira Ramosa,*

Lígia Maria Moreira Dumont

\begin{abstract}
RESUMO: As histórias em quadrinhos são um gênero e formato de leitura presentes em todo o mundo, que se caracterizam por veicular narrativas que podem ser empregadas para uma série de finalidades. A pesquisa analisa seis imagens e histórias protagonizadas por super-heróis e por principais personagens de quadrinhos, produzidas em decorrência do Coronavírus, com o objetivo de compreender as formas criadas para informar os cuidados de prevenção ao Coronavírus. Recorre-se à narratologia como método de análise das imagens e histórias, destacando-se o tema, enredo, ambiente e tempo cronológico das histórias, bem como as ações realizadas pelos personagens. Evidencia-se que elas transmitem informações condizentes com o momento sócio histórico ocasionado pelo Coronavírus, destacando ações do cotidiano das pessoas, porém vivenciadas pelos protagonistas das histórias.
\end{abstract}

Palavras-chave: Histórias em Quadrinhos; Leitura de Ficção e Coronavírus; Leitura - Heróis e Protagonistas.

ABSTRACT: Comic books are a genre and reading format present throughout the world, which convey narratives that can be used for a number of purposes. This research analyzes six images and stories starring superheroes and main comic book characters, produced as a result of the Coronavirus, with the aim of understanding the ways created to inform the preventive care of the Coronavirus. Narratology is used as a method of analyzing images and stories, highlighting the theme, plot, environment and chronological time of the stories, as well as the actions taken by the characters. It is evident that they transmit information consistent with the socio-historical moment caused by the Coronavirus, highlighting people's daily actions, however experienced by the stories' main characters.

Keywords: Comic Books; Fictional Reading and Coronavirus; Reading - Heroes and Main Characters.

\footnotetext{
${ }^{a}$ Faculdade de Informação e Comunicação, Universidade Federal de Goiás, Goiânia, GO, Brasil.

b Programa de Pós-graduação em Ciência da Informação, Universidade Federal de Minas Gerais, Belo Horizonte, MG, Brasil.

*Correspondência para/Correspondence to: Rubem Borges Teixeira Ramos. E-mail: rubemborges@ufg.br. Endereço institucional: Universidade Federal de Goiás, Faculdade de Informação e Comunicação. Avenida Esperança s/n, Câmpus Samambaia. CEP 74690-900 - Goiânia - Goiás - Brasil.
}

Recebido em/Received: 15/08/2020; Aprovado em/Approved: 20/11/2020.

Artigo publicado em acesso aberto sob licença CC BY 4.0 Internacional $\subseteq()$ 


\section{INTRODUÇÃO}

As histórias em quadrinhos são um formato de leitura produzido, difundido e consumido em diversas culturas e sociedades em todo o mundo. Um dos fatores responsáveis pela grande aceitação de diferentes públicos aos quadrinhos deve-se à capacidade de seus personagens incorporarem e reproduzirem posturas, atitudes e crenças em muito semelhantes às de seus leitores, os enredos presentes nestas histórias exibirem situações, eventos e contextos similares a vários aspectos e nuances da vida cotidiana (RAMOS, 2017). Tal vertente vem crescendo e apresentando aporte teórico, endossado por estudos e pesquisas de diversos campos disciplinares que dialogam com a temática leitura.

As histórias em quadrinhos podem englobar variadas possibilidades e campos artísticos em sua confecção, como a ilustração, o teatro, a literatura, a caricatura e o cinema, por exemplo. Essa peculiaridade traz ao gênero uma riqueza e uma complexidade próprias onde, segundo Barbieri' (1998 apud Vergueiro, 2017, p. 16), "elementos narrativos de várias manifestações artísticas ou linguagens são explorados". Tal pluralidade se faz constar presente na atualidade pela variedade de estilos e gêneros narrativos em que os quadrinhos são publicados, o que inclui produções tanto ficcionais quanto factuais de variadas temáticas, como infantis, policiais, de aventura, de terror, de super-heróis, eróticas, filosóficas, jornalísticas, acadêmicas, dentre outras.

Ao se considerar essa gama de possibilidades, as histórias em quadrinhos podem ser recorridas por diversos indivíduos e grupos, desde a confecção de suas narrativas até sua leitura propriamente dita, para uma série de finalidades, como, por exemplo conhecer, de forma lúdica, eventos que ocorrem no mundo e as relações estabelecidas entre seus personagens e estes eventos. Podem retratar, inclusive e comumente, a realidade, mesmo em se tratando de estados ou situações de emergência, como é o atual caso da pandemia mundial causada pelo COVID-19, que demanda viabilidade ao acesso, recuperação e representação de informações essenciais à saúde e vida humanas.

Assim, o elemento norteador do presente artigo se traduz da seguinte forma: quando uma pandemia assola o mundo real, a sua veiculação nas histórias em quadrinhos baseia-se efetivamente nesta mesma realidade? Em caso afirmativo, com que grau de veracidade e de fidelidade retratam a realidade? Para tal averiguação, utilizou-se como método a identificação e análise das formas com que o COVID-19 vem sendo abordado nas histórias em quadrinhos, bem como as ações, posturas e decisões executadas pelos personagens quanto ao cuidado, prevenção e manutenção da saúde, verificando o quão próximas e condizentes se encontram das práticas recomendadas pelos órgãos globais de saúde.

Iser (1999), ressalta a importância e a valorização da leitura ficcional. O autor pontua a influência que uma obra exerce frente a seu público leitor, estabelecendo que o ato de ler em si se caracteriza como algo que permite ao leitor reelaborar a leitura por meio de reflexões, ponderações e inferências com a realidade. Iser demarcou a mudança dos holofotes dos estudos da literatura, antes presa ao texto, para o seu leitor. Descreve a leitura como um processo dinâmico entre estas duas entidades, texto e leitor. E tal correlação só se faz, quando [...] "o texto se faz presente no leitor como correlato da consciência” (ISER, 1999, p. 9). 
Ainda de acordo com o autor:

\begin{abstract}
A relação entre o texto e o leitor se caracteriza pelo fato de estarmos diretamente envolvidos e, ao mesmo tempo, de sermos transcendidos por aquilo que nos envolvemos. O leitor se move constantemente no texto, presenciando-o somente em fases; dados do texto estão presentes em cada uma delas, mas ao mesmo tempo parecem ser inadequados. Pois os dados textuais são sempre mais do que o leitor é capaz de presenciar neles no momento da leitura. Em consequência, o objeto do texto não é idêntico a nenhum de seus modos de realização no fluxo temporal da leitura, razão pela qual sua totalidade necessita de sínteses para poder se concretizar. Graças a essas sínteses, o texto se traduz para a consciência do leitor, de modo que o dado textual começa a constituir-se como correlato da consciência mediante a sucessão das sínteses (Iser, 1999, p.12-13).
\end{abstract}

A estética da recepção de Iser presume que o texto retém um potencial para fornecer estímulo e compete ao leitor acessá-lo e atualizá-lo, por intermédio de sua imaginação. A visão e opinião do leitor lançadas perante uma leitura, apontando a sua capacidade de apreender o conteúdo veiculado no texto, sobretudo por suas lembranças e expectativas, Ihe permite agrupar os signos textuais, fazendo com que a identificação das relações contidas no texto se torne coerente.

A leitura de histórias em quadrinhos, nessa ótica, pode ser também compreendida como uma leitura de preenchimentos, já que o leitor é convidado a empregar sua imaginação e também conhecimentos previamente adquiridos e introjetados em sua mente, para conectar um ou mais momentos representados na narrativa, recriando-os em seu íntimo de modo a concluir mentalmente o desenrolar da trama ali contida e interpretar o conteúdo da história. Tais processos e efeitos se explicam pela necessidade ou característica humana, conforme ressalta Iser (1999), de se ficcionalizar a existência, devido ao fato deste gênero literário reter a capacidade de revelar ao leitor aspectos e nuances sobre si próprio.

A metodologia da pesquisa apoiou-se na narratologia, pois, apesar de se tratar de um método relativamente novo junto à Ciência da Informação, é capaz de fornecer, de acordo com Gancho (2002), métodos válidos no que tange à análise de personagens e de enredos apresentados em uma narrativa. Ao todo, foram analisadas seis histórias e imagens de quadrinhos, produzidas no ano de 2020: duas da Marvel Comics, duas da DC Comics e duas da Turma da Mônica. A análise empreendida teve caráter descritivo por intermédio da narratologia, de modo a evidenciar o detalhamento das histórias. As narrativas em quadrinhos escolhidas refletem práticas e atitudes relativas à prevenção ao COVID-19 e ações praticadas durante o isolamento social de grande parte de indivíduos em várias culturas no mundo. Lembrando que até o presente momento, ainda não existe vacina ou outra forma de tratamento mais específico da doença.

\title{
LEITURA CIÊNCIA DA INFORMAÇÃO
}

Para se compreender a leitura, é necessário partir-se do princípio da necessidade expressa de se aprender a decodificar caracteres e símbolos. Após tal aprendizado, o leitor se forma e é capaz de processar e dar sentido próprio ao que lê. Entretanto, no mundo contemporâneo, já se tem como consenso que tal fundamento básico é insuficiente para traduzir todo o fenômeno da ação leitura, seu potencial, já que ela é 
um ato e experiência vastamente ricos e seus estudos vão além do aspecto processual, envolvem fatores que dialogam com diferentes campos disciplinares.

Ao prosseguir o aprendizado e praticar mais leituras, percebe-se a necessidade demonstrada pelo leitor quanto a incorporar e compreender as relações que se estabelecem entre o conteúdo escrito e a realidade. Essa vontade envolve a capacidade do leitor de estabelecer leituras e questionar, de forma crítica e interpretativa, o teor lido, de modo a, posteriormente, iniciar trocas de ideias e de informações com os demais indivíduos.

De acordo com Chartier (2001, p.29), é imprescindível ao estudo e a compreensão da leitura [...] "reconhecer o vínculo essencial entre o texto em sua materialidade, que suporta os textos e as práticas de apropriação, que são as leituras". Isso implica no reconhecimento da leitura como um fenômeno não somente baseado em caráter puramente linguístico, vai além, fruto das interações estabelecidas entre texto e leitor. A leitura é um processo de percepção e de compreensão acerca do mundo em que se insere, que culmina na produção e construção de sentidos.

Quando um leitor desenvolve a ação leitura, ele é convidado a recompor o texto. Ao mesmo tempo em que se relaciona com o conteúdo lido, ele acaba por transcendê-lo por meio de atualizações, associações relacionadas a conhecimentos previamente adquiridos e introjetados. Isso significa atribuir à leitura um sentido composto, sendo uma performance ao mesmo tempo dinâmica e uma atividade de síntese, a qual demanda do leitor uma postura proativa, indo além do que os dados textuais lhe informam, adicionando a eles outros dados e fornecendo-lhes uma configuração diferente, em muitos aspectos mais aprofundados, de modo que um novo texto é formado.

$\mathrm{O}$ ato de ler, quando analisado sob os preceitos e teorias da Ciência da Informação, tem o princípio de que todo tipo de leitura é capaz de agregar valor ao seu leitor, gerar conhecimento (DUMONT, 2017). As pesquisas na área, ao analisarem a circulação da informação entre os indivíduos que compõem a sociedade, vêm demonstrando as maneiras como o leitor pode apropriar-se da informação.

Em seus estudos sobre leitura baseados em diferentes campos disciplinares, Dumont (2001, 2017) constatou a existência de três elementos chaves, que interagem de forma interconectada, os quais levam o leitor a se apropriar de informações, fenômeno que a autora cunhou como componentes da efetivação da leitura. São eles: A) o contexto - o quão familiar um leitor se encontra acerca dos temas presentes em uma leitura, bem como a capacidade de compreensão do conteúdo lido como resultado da percepção entre o texto e o contexto do leitor; b) a motivação - os estímulos (atração, desejo, curiosidade, interesse, dentre outros) que motivam a ação da leitura e c) o sentido capacidade do leitor de compreender o sentido e o significado da escrita contida em um texto, consolidando-se em uma estrutura plausível. A apropriação de conhecimentos ocorre, portanto, no momento em que no mínimo estes três componentes - contexto, motivação e sentido - se unem no ato da leitura, conforme ilustra a figura abaixo: 


\section{Figura 1: Representação dos componentes da leitura}

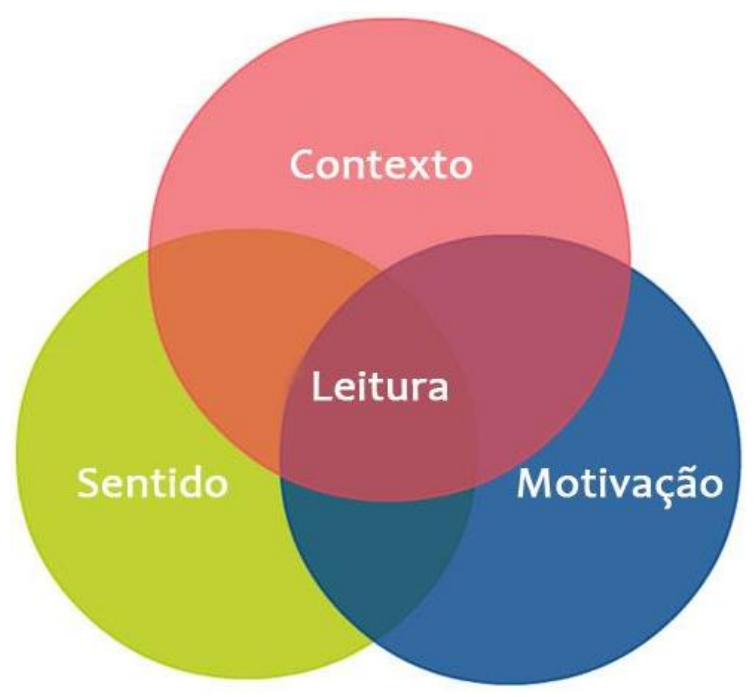

FONTE: Dumont, 2017.

\section{HISTÓRIAS EM QUADRINHOS}

Mesmo diante da simplicidade em sua composição básica, encontrar uma definição sobre histórias em quadrinhos que venha a satisfazer completamente é uma tarefa laboriosa, que se encontra em um processo contínuo de revisão e de atualização. Vergueiro (1998, p.120) assim as conceitua:

[...] constituem um meio de comunicação de massa que agrega dois códigos distintos para a transmissão de uma mensagem: o linguístico, presente nas palavras utilizadas nos elementos narrativos, na expressão dos diversos personagens e na representação dos diversos sons, e o pictórico, constituído pela representação de pessoas, objetos, meio ambiente, ideias abstratas e/ou esotéricas, etc.

Eisner (1999), empregou o termo arte sequencial, ressaltando a combinação dos códigos pictórico e linguístico para se narrar uma história. A partir desse trabalho, McCloud (2005) procurou ampliar a noção estabelecida, ressaltando a sequência dos quadros para a fluidez e a compreensão da história veiculada, que culminou em própria definição de histórias em quadrinhos, como sendo [...] "imagens pictóricas e outras, justapostas em sequência deliberada, destinadas a transmitir informações e/ou produzir uma resposta no espectador" (p.20).

O leitor de quadrinhos acessa tanto os requadros com imagens e textos da história, quanto também os espaços em branco posicionados entre os requadros. No primeiro caso, McCloud (2005, p. 63) denomina tal processo de "conclusão", pois trata-se do [...] "fenômeno de observar as partes, mas perceber o todo". É um esforço cognitivo, empregado no sentido de alcançar a integralidade de algo - uma imagem, um fato ou mesmo um evento, por exemplo - que é apresentado de forma parcial ou incompleta, recorrendo a experiência ou conhecimento prévios. Ainda que esse acesso ocorra de forma individual, como, por exemplo, ao olhar a capa de uma revista em quadrinhos, uma série de elementos podem lhe ser dados pelo desenhista, inclusive do ponto de vista narrativo, como rostos, cenários ou balões de fala parcialmente retratados. Inclusive para gerar suspense, expectativa ou até humor, exigindo do leitor esforço de 
imaginação para completá-lo e o impulsionando a iniciar a leitura da revista. No que se refere aos espaços em branco, que McCloud denomina "sarjeta", podem ser compreendidos como lacunas que interconectam os requadros. Compete também ao leitor preencher esses espaços, recorrendo para tanto ao processo de conclusão, que [...] "nos permite conectar estes momentos e concluir mentalmente uma realidade contínua unificada" (MCCLOUD, 2005, p.67).

Ao destacar os quadrinhos também como formatos de leitura capazes de informar, é possível associá-los ao conceito de fonte de informação. As imagens componentes de uma história em quadrinhos possibilitam ao seu leitor recriar cenários e contextos oriundos de uma gama variada de temáticas, pois contêm informações registradas que podem transmitir informação, conforme defendem Araújo e Fachin (2015, p.84):

\begin{abstract}
As fontes de informações são registros utilizados ao longo da vida do ser humano, possibilitando ampliar a visão do mundo em que vive e sobre as coisas que estão a sua volta. [...] são aquelas que nos permitem criar, recriar e ter acesso ao conhecimento sobre um assunto ou área de nosso interesse ou pesquisas. De modo que, as fontes de informações são referências sobre o que está registrado e disponível ao ser humano, possibilitando reinventar ou compreender melhor seu objeto de estudo.
\end{abstract}

Diante dessa conceituação, a definição de McCloud se torna assaz importante para a compreensão acadêmica dos quadrinhos, em particular para a Ciência da Informação, ao considerá-los também como uma fonte capaz de veicular informações. Pode-se presumir que eles tenham potencial para serem empregados junto à produção e transmissão do conhecimento, fornecendo ao seu leitor a atribuição de sentidos e o alcance de significados através de sua própria subjetividade.

Tal afirmação parece encontrar subsídio junto às definições contemporâneas de informação, particularmente à luz do pensamento de Capurro e Hjørland (2007, p.162), quando afirmam que [...] "a tendência tem sido de re-humanizar o conceito de informação; isto é, colocá-la no contexto cultural”. Ao se considerar que a informação, no entender dos autores, depende diretamente de um contexto cultural para seu efetivo entendimento, torna-se viável pensar que as situações retratadas nas páginas das histórias em quadrinhos carregam em muito este conceito re-humanizado de informação, já que elas remetem o leitor, durante e após o ato de ler, a fatos, eventos e acontecimentos ocorridos em diversos contextos que participam em seu cotidiano, como o profissional, o familiar, o das relações afetivo-amorosas, dentre outros. No que se refere à compreensão das fontes de informação na Ciência da Informação, as histórias em quadrinhos podem ser consideradas como um exemplo apropriado, já que tal formato de leitura, conforme corrobora Oliveira (2014, p.140), "desperta, veicula uma cognição integral vinculada à leitura de mundo dos sujeitos”.

Combinando imagens e palavras, as histórias em quadrinhos foram publicadas inicialmente em tiras nos jornais. Somente se fizeram presentes em seu meio mais tradicional - as revistas - a partir dos anos 1930, o que contribuiu para sua popularização e aceitação em vários países do mundo, apresentando uma variedade de gêneros e em uma miríade de temas. As revistas continuam sendo populares até hoje, mas é possível se encontrar quadrinhos publicados em diversos outros formatos, o que também possibilitou a sua inserção em outros ambientes além da banca de jornais e revistas, como livrarias, bibliotecas, gibitecas (bibliotecas especializadas em histórias em quadrinhos) e as gibiterias (espaços voltados a comercialização de quadrinhos e produtos derivados). 
Ao se acompanhar a evolução da publicação dos quadrinhos, e a constante presença deles até hoje entre seus leitores, presume-se que a informação neles contida atinge o seu caráter social. Ao relatar sobre o conceito de informação em movimento, Marteleto (2003) observa a presença e a fluidez da mesma, de forma contínua, no cotidiano de todos. A autora compreende que a informação é um produto de interações humanas, considerando para tanto sua utilidade, quem a utiliza e os contextos socioculturais em que ela é empregada. Assim, focando-se a informação pelo prisma sociocultural, é necessário dar a devida atenção quanto a sua constituição e compreensão.

Reconhecendo os quadrinhos como uma manifestação cultural da humanidade, pelo supracitado uso combinado de imagens e palavras, além da sua inserção e difusão em várias sociedades em todo o mundo, identificar exemplos de histórias que abarquem de um ou mais modos a pandemia resultante do COVID-19, tal qual se concebe como realidade social atual, pode levar a resultados importantes, no que tange a comprovação do conceito reumanizado de informação.

\section{NARRATOLOGIA}

Uma das expressões pelas quais as histórias em quadrinhos são mais reconhecidas em todo o mundo ocorre justamente com seus personagens. Por intermédio de suas posturas, pensamentos, falas e ações, juntamente com o desenrolar da trama, é que se dá o teor da história. Tanto o roteirista quanto o desenhista procuram desenvolver suas histórias de modo a expressar um ou mais pensamentos que possuem acerca de um ou mais personagens que tem à disposição, bem como do cenário e do contexto em que serão alocados. Não é difícil de se supor que grande parte dessa ação dos autores dos quadrinhos tenha por base suas próprias crenças e convicções, acerca do mundo e da sociedade em que vivem. E ao colocá-las nos requadros, formam assim a trama da história, acabando por se tornarem os autores — roteirista e desenhista produtores da informação.

Ao versar sobre a constituição da identidade própria, Barbosa (2003) vai além, defendendo a presença da ficção e da experiência como instâncias constituintes da vida humana, e que a interação entre ambas se potencializa quando disposta no campo da narrativa.

Narrar um ou mais fatos, eventos, instâncias ou acontecimentos não é necessariamente uma reprodução fiel, podendo se tratar se uma versão dos mesmos, que tem por base tanto a percepção de quem narra quanto seus conceitos, noções, valores e ideias. Vai-se, portanto, ao encontro da perspectiva de Barbosa (2003), compreendendo a narrativa como um instrumento que relata e retrata versões parciais de uma ou mais realidades, como resultado da visão do autor e de seu arcabouço de conhecimento previamente adquirido. Assim, ao se estudar uma ou mais narrativas, é sensato pressupor que as mesmas são fruto de lembranças do narrador, e que são postas em prática quando transformam eventos em episódios e atores em personagens.

Ao se identificar e proceder-se à análise de narrativas, é importante evidenciar que elas expõem e retratam histórias, compostas por uma série de elementos, capazes de fornecer o sentido que o autor pretende imprimir a essas histórias. A estrutura de uma narrativa, de acordo com Gancho (2002), é fundamentada em cinco elementos: 
a) Enredo: o conjunto de fatos presentes em uma história. Trata-se do teor da narrativa, das ações desempenhadas dentro de um ou mais temas abordados pelo autor.

b) Personagens: o ser ou entidade a quem se atribui a responsabilidade pelo desenrolar do enredo. Se aplica tanto aquele que protagoniza uma ou mais ações, quanto àqueles que são alvo ou se encontram envolvidos - direta ou indiretamente - na execução ou mesmo nos resultados dessas ações. Esses indivíduos podem apresentar uma série de atributos físicos, mentais, emocionais e sociais, o que contribui para reconhecê-los e endossar suas posturas e decisões ao longo do desenrolar do enredo.

c) Noção de tempo: registro da época ou era em que a narrativa ocorre, bem como sua duração e sua passagem. Ainda que possa não ser totalmente preciso, fornece ao público alvo da narrativa uma ideia, que pode se referir tanto ao tempo cronológico - aquele mensurado com a passagem do tempo propriamente dito, observado via a ocorrência de fenômenos naturais, quanto ao tempo psicológico, percebido através de memórias, lembranças, não necessariamente atreladas a um momento ou linha mensurável no tempo, mas sim na ocorrência de fatos e eventos, bem como no acúmulo de conhecimento e de experiências de vida.

d) Noção de espaço: localidades onde se desenrolam as ações presentes na narrativa. Seu principal propósito é o de situar as ações desenvolvidas pelas personagens, bem como fornecer ao público alvo um vínculo junto a elas.

e) Narrador: trata-se do principal elemento que concede estrutura e fundamentação à história, podendo ser um personagem da mesma, cuja função é intermediar a relação entre enredo e público alvo, tornando o primeiro palatável ao segundo, ou mesmo o autor da trama, quer ele a desenvolva em primeira ou terceira pessoa.

\section{METODOLOGIA}

As histórias em quadrinhos são um formato de leitura que recorre à combinação de códigos linguístico - que se faz presente nas palavras ditas por personagens, nos elementos pertinentes a narrativa deste meio em particular e também junto a representação de diversos sons - e pictórico / imagético — que é a representação dos personagens propriamente ditos, além dos cenários, contextos, objetos e até mesmo ideias reais ou ficcionais diretamente relacionadas a narrativa - para a veiculação de narrativas, a presente pesquisa apresenta uma abordagem qualitativa já que, segundo Minayo (2011), procura aprofundar a importância de se compreender uma determinada realidade como um fenômeno cultural, trabalhando com o universo dos significados, dos motivos, das aspirações, das crenças, dos valores e das atitudes.

As imagens analisadas podem se caracterizar tanto por se tratar de uma imagem isolada, quanto pela sequencialidade justaposta de imagens. Deve-se levar em consideração que, mesmo se apresentando de forma isolada e não sequencial, as ilustrações escolhidas para a análise empregam a combinação dos códigos linguísticos, a presença de legendas e falas atribuidas a personagens e os códigos pictórico e imagético, com a inclusão de personagens oriundos dos quadrinhos, os super-heróis e os membros da Turma da Mônica.

Torna-se necessário ressaltar as formas de discurso veiculadas nessa narrativa, de acordo com Vergueiro (2017, p.96): 
No caso das histórias em quadrinhos, todos os aspectos inerentes a sua linguagem podem ser objeto da análise do discurso, desde as formas de manifestação dos personagens [...] e os elementos discursivos exclusivos dos quadrinhos [...]. Para a análise do discurso, todas as manifestações verbais são consideradas dentro de um contexto sócio histórico.

A partir dessa afirmativa, tanto as palavras quanto os desenhos contidos nos quadrinhos, entendidos também como seus elementos discursivos, podem ser analisados dentro do momento e do contexto sócio histórico de pandemia causada pelo COVID-19. Procura-se na análise ressaltar as formas pelas quais a atual realidade é abordada nas histórias em quadrinhos, destacando ações, posturas e decisões demonstradas pelos personagens quanto ao cuidado, prevenção e manutenção da saúde, no intuito de evidenciar que elas são compatíveis e condizentes com as ações postas em prática, tanto pelos leitores quanto pela população em geral.

A análise apresentada pode ser classificada como uma pesquisa descritiva, já que tem por objetivo, conforme afirma Gil (2002), a descrição de um ou mais fenômenos e características de uma população ou objeto selecionado. No presente caso, a descrição remete ao enredo proposto na narrativa dos quadrinhos analisados, bem como à ambientação e à forma como os personagens são retratados.

A técnica de pesquisa utilizada foi a narratologia, conforme classifica Gancho (2002), indica cinco elementos de análise a serem levados em consideração: o enredo; os personagens; a noção de tempo; a noção de espaço; e o narrador. As histórias ficcionais formam uma narrativa que pode ser submetida a análises, de modo que as características que constituem os personagens e os enredos nos quais eles estão inseridos possam ser conceituadas e explicadas. Foram analisadas histórias publicadas a partir de março de 2020, quando do reconhecimento pela Organização Mundial da Saúde (OMS) de que o surto da doença causada pelo novo Corona vírus constitui uma emergência de saúde pública de importância internacional e de sua caracterização como uma pandemia, de acordo com as regulamentações sanitárias vigentes.

\section{NARRATIVAS DAS HISTÓRIAS EM QUADRINHOS E A PANDEMIA MUNDIAL DO COVID - 19}

$\mathrm{Na}$ contemporaneidade, diversos gêneros dos quadrinhos em todo o mundo já produziram tiras, charges e narrativas que abordam o COVID-19 e suas consequências, procurando dar ênfase ao enfrentamento que a humanidade tem demonstrado para com esta pandemia. Quer seja através das ciências da saúde, quando profissionais de várias áreas se empenham arduamente no seu combate, quanto nas ações cotidianas de leitura, que retratam personagens ficcionais que precisam se adaptar às rotinas e restrições do assim chamado 'novo normal', como condição imposta pelas restrições à vida social em seus mais diversos aspectos.

A análise descrita a seguir se baseou fortemente na noção de ficcionalização da vivência humana defendida por Iser (1999), representada pelo cotidiano dos superheróis e protagonistas das histórias em quadrinhos e das imagens selecionadas, bem como nos três fatores de efetivação da leitura defendidos por Dumont (2001, 2017), quais sejam, contexto, motivação e sentido, que se articulam harmoniosamente com a narratologia de Gancho (2002). 


\section{Marvel Comics}

A Marvel Comics fez uma opção por inserir alguns de seus super-heróis justamente neste novo cenário, enfrentado não apenas por seus leitores, mas por toda a humanidade. E o fez desenvolvendo uma série de histórias em quadrinhos curtas, publicadas sempre aos domingos entre os meses de julho e agosto de $2020 \mathrm{em}$ seu perfil oficial do Instagram - https://www.instagram.com/marvel/. Nessas histórias, alguns dos principais personagens da editora são dispostos em contextos e situações em que devem lidar de alguma forma com as repercussões e restrições a vida social, advindas da pandemia instaurada e da consequente quarentena, conforme se constata a seguir:

Figura 2 - Homem-Aranha \#heroesathome

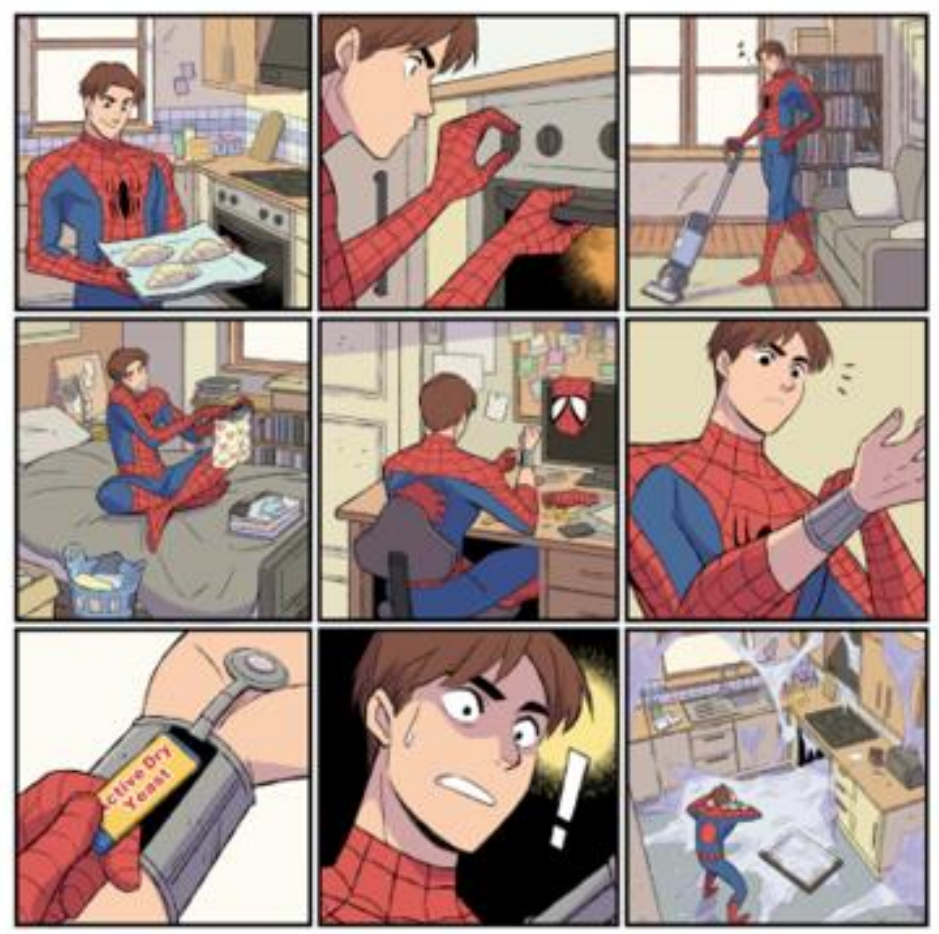

Fonte: Perfil oficial da Marvel Comics no Instagram² 
Quadro 1 - Narratologia em Homem-aranha \#heroesathome

\begin{tabular}{|c|c|}
\hline CATEGORIA & ANÁLISE \\
\hline Enredo & $\begin{array}{l}\text { O Homem-Aranha (Peter Parker) decidiu passar o tempo realizando uma série de } \\
\text { tarefas domésticas em sua casa - assar croissants, passar o aspirador de pó, dobrar } \\
\text { as roupas lavadas, enquanto conversa ao telefone e ajustar o seu disparador de teias } \\
\text { (ressalta-se, uma tarefa doméstica bastante peculiar a este personagem). } \\
\text { Infelizmente, o herói descobriu que, acidentalmente, trocou o fermento para } \\
\text { assados pelo cartucho onde armazena seu fluido de teias. Quando se deu conta do } \\
\text { fato, sua cozinha ficou repleta de fluidos de teias espalhadas por todo o cômodo. }\end{array}$ \\
\hline Personagens & $\begin{array}{l}\text { O Homem-Aranha (Peter Parker) é frequentemente retratado como um indivíduo } \\
\text { azarado, o que não foge ao enredo desta narrativa e contribui também para os } \\
\text { leitores reconhecerem o personagem e a si mesmos, já que ações atrapalhadas e } \\
\text { acidentes na cozinha são fatos típicos de todos os lares. }\end{array}$ \\
\hline Noção de Tempo & $\begin{array}{l}\text { Tempo psicológico - não é possível precisar o período exato em que esta narrativa } \\
\text { ocorreu. Mas a mesma evidencia uma série de eventos cotidianos, de ordem } \\
\text { doméstica, bem como o resultado desastroso de um deles, que em muito ressaltam } \\
\text { a experiência de vida dos leitores. Inclusive, é de se supor que em virtude do } \\
\text { confinamento, as pessoas passaram a desempenhar com mais frequência e volume } \\
\text { atividades domésticas. }\end{array}$ \\
\hline Noção de Espaço & $\begin{array}{l}\text { A ação ocorre em um ambiente residencial - diversos cômodos de um lar, com } \\
\text { destaque para a cozinha. O vínculo com o público leitor se estabelece de forma } \\
\text { direta, pois a maioria das pessoas reside em um lar, que possui uma cozinha, com } \\
\text { seus aparelhos e utensílios típicos e comuns. }\end{array}$ \\
\hline Narrador & $\begin{array}{l}\text { Peter Parker é o narrador desta história, pois ele é o elo que intermedia as ações da } \\
\text { trama (realizar tarefas domésticas, ter um descuido e causar um acidente em um } \\
\text { deles) e o público leitor. }\end{array}$ \\
\hline
\end{tabular}

Fonte: Elaborado pelos autores, 2020. 
Figura 3 - Wolverine \#heroesathome

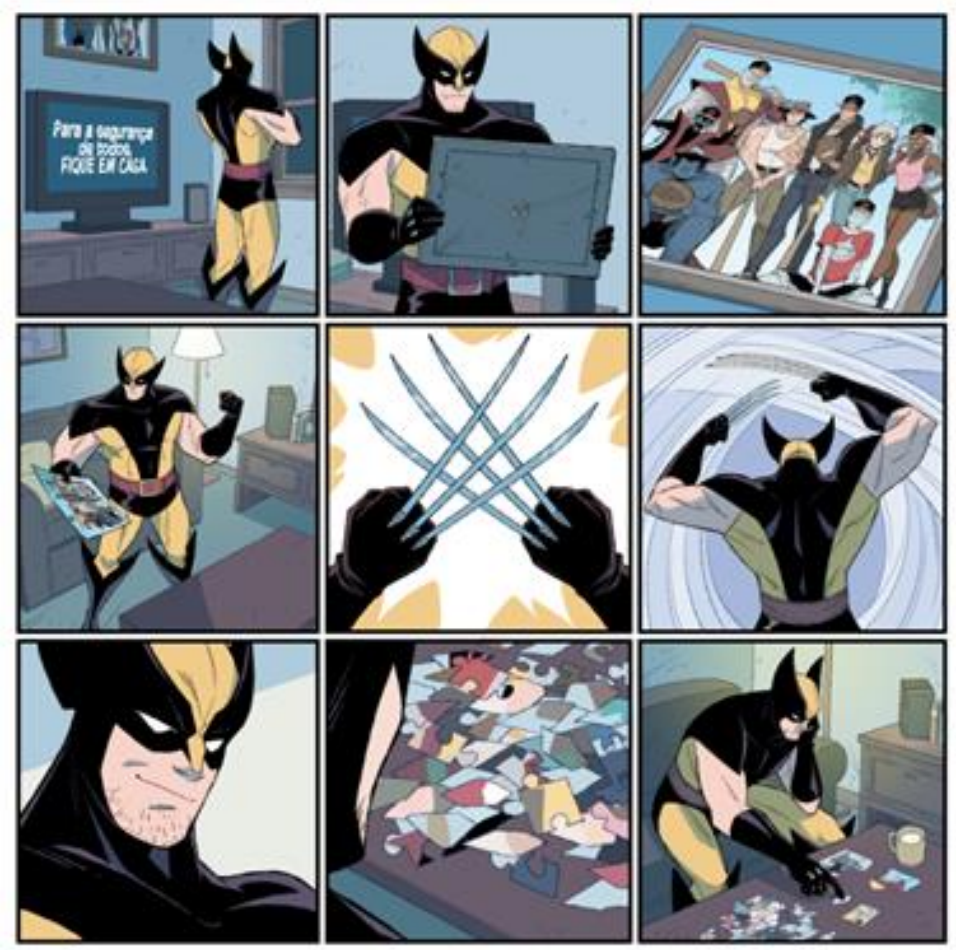

Fonte: Perfil oficial da Marvel Comics no Instagram³

\section{Quadro 2 - Narratologia em Wolverine \#heroesathome}

\begin{tabular}{|l|l|}
\hline \multicolumn{1}{|c|}{ CATEGORIA } & \multicolumn{1}{c|}{ ANÁLISE } \\
\hline Enredo & $\begin{array}{l}\text { Wolverine aparenta estar entediado durante o período de isolamento social. } \\
\text { Encontrando um porta-retratos com uma foto sua com outros X-Men, ele decide } \\
\text { usar suas garras para transformar a foto em um quebra-cabeça, de modo a remontá- } \\
\text { la, encontrando assim uma forma de passar o tempo do isolamento. }\end{array}$ \\
\hline Personagens & $\begin{array}{l}\text { A atitude de Wolverine é justificada na medida em que o personagem é conhecido } \\
\text { também por ser impaciente. De modo a passar o tempo, de uma forma que lhe é } \\
\text { bem peculiar, Wolverine emprega suas garras para criar um quebra cabeça a partir } \\
\text { de uma foto sua com os outros integrantes dos X-Men, passando logo em seguida a } \\
\text { remontá-la. }\end{array}$ \\
\hline Noção de Tempo & $\begin{array}{l}\text { Tempo psicológico - não é possível precisar o período exato em que esta narrativa } \\
\text { ocorreu. Acredita-se ser o do isolamento imposto pelo COVID-19. E o passatempo de } \\
\text { remontar um quebra-cabeça, peça a peça, é um bom exemplo de como lidar de } \\
\text { forma lúdica com uma restrição imposta por motivo de força maior, ou até de } \\
\text { controlar a impaciência. }\end{array}$ \\
\hline Noção de Espaço & $\begin{array}{l}\text { A ação ocorre em um ambiente residencial, especificamente a sala de estar, cômodo } \\
\text { comum a diversas habitações, o que contribui para o estabelecimento do vínculo } \\
\text { junto ao público leitor. }\end{array}$ \\
\hline Narrador & $\begin{array}{l}\text { Wolverine é o personagem e o narrador desta história, agindo como o elo entre a } \\
\text { narrativa - criar um quebra-cabeça para passar o tempo - e o público leitor, que é } \\
\text { capaz de se identificar tanto com o tédio do isolamento quanto com a ação de jogar } \\
\text { um jogo simples de modo a passar o tempo. }\end{array}$ \\
\hline
\end{tabular}

Fonte: Elaborado pelos autores, 2020.

${ }_{3}^{3}$ Disponível em: https://www.instagram.com/p/CDZCJiVFIWM/. Acesso em ago. 2020 


\section{Comics}

Ao contrário de sua mais distinta e direta concorrente em gênero dos quadrinhos, a DC Comics escolheu seguir por uma linha editorial ligeiramente diferente, não desenvolvendo uma série de histórias específicas para o período da pandemia, mas postando em seu perfil oficial do Instagram - https://www.instagram.com/dccomics/ alguns de seus personagens - quer seja em imagens isoladas, ou mesmo em pequenas animações, como é o caso em Batman Lego ${ }^{4}$ - em ações e eventos típicos do mundo contemporâneo, destacando a iniciativa com a hashtag \#ConnectedTogether.

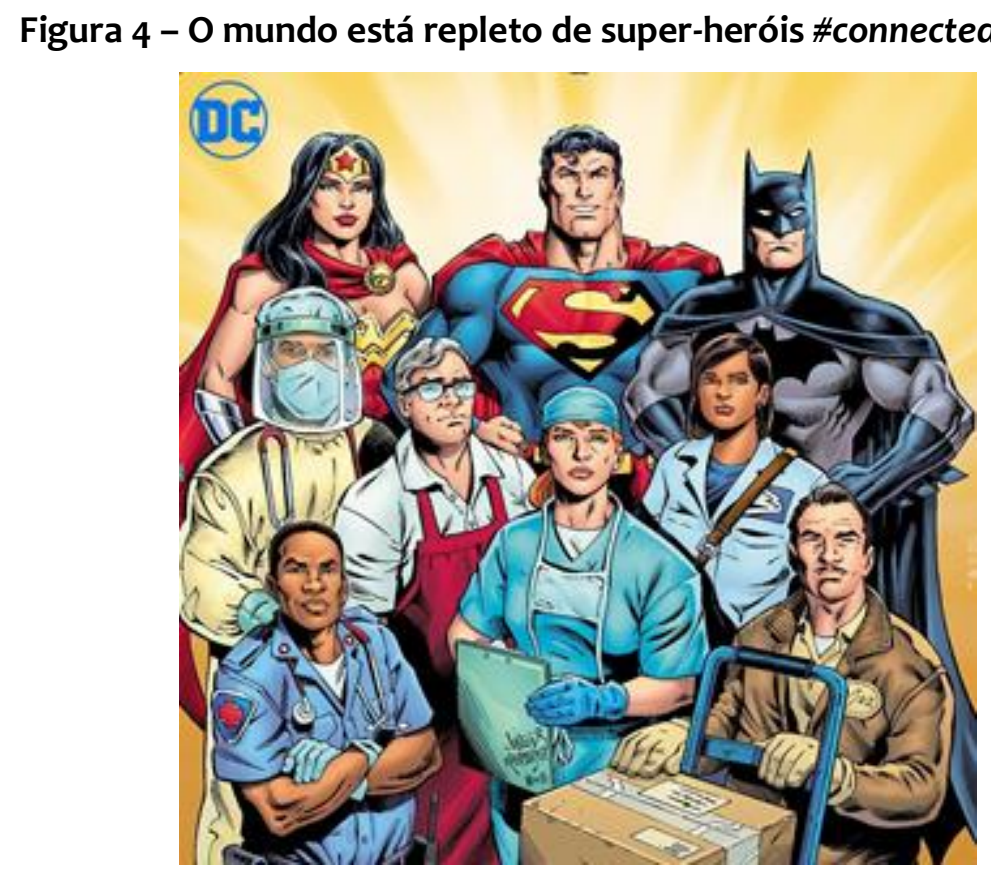

Fonte: Perfil oficial da DC Comics no Instagram 5 .

\footnotetext{
4 Disponível em <https://www.instagram.com/p/B_sW_UJA2Aq/> Acesso em ago. 2020.

${ }^{5}$ Disponível em <https://www.instagram.com/p/B-7clE-jTcp/> Acesso em ago. 2020.
} 


\section{QUADRO 3 - NARRATOLOGIA EM O MUNDO ESTÁ REPLETO DE SUPER-HERÓIS \#CONNECTEDTOGETHER}

\begin{tabular}{|l|l|}
\hline \multicolumn{1}{|c|}{ CATEGORIA } & \multicolumn{1}{c|}{ ANÁLISE } \\
\hline Enredo & $\begin{array}{l}\text { Os três maiores personagens da DC Comics - Super-Homem, Mulher Maravilha e } \\
\text { Batman - rendem homenagem a profissionais tidos como essenciais durante o } \\
\text { período da pandemia imposta, como os da saúde e os entregadores. }\end{array}$ \\
\hline Personagens & $\begin{array}{l}\text { Super-Homem, Mulher Maravilha e Batman (personagens ficcionais), e profissionais } \\
\text { que desempenham serviços essenciais à manutenção da vida humana neste período } \\
\text { de isolamento social (Médicos, paramédicos, cirurgióes, entregadores, } \\
\text { comerciantes dos gêneros alimentícios), todos facilmente reconhecidos pelos seus } \\
\text { uniformes e apetrechos. }\end{array}$ \\
\hline Noção de Tempo & $\begin{array}{l}\text { Tempo psicológico - não é possível precisar o período exato em que esta narrativa } \\
\text { ocorreu. Atribui-se ao tempo do isolamento imposto aos tratamentos de saúde pelo } \\
\text { COVID-19. }\end{array}$ \\
\hline Noção de Espaço & $\begin{array}{l}\text { Não é possível precisar a localidade desta imagem, com base nos elementos } \\
\text { fornecidos pela figura. }\end{array}$ \\
\hline \multirow{5}{*}{ Narrador } & $\begin{array}{l}\text { Todos os personagens retratados nessa imagem são os narradores da história, uma } \\
\text { vez que coloca no mesmo patamar dos três personagens - Super-Homem, Mulher- } \\
\text { Maravilha e Batman - os profissionais da saúde, comerciantes dos gêneros } \\
\text { alimentícios e entregadores, nesse período que restringe o exercício de atividades } \\
\text { sociais. Trata-se de uma homenagem, ao apontá-los como verdadeiros super-heróis, } \\
\text { a imagem exerce o canal entre os heróis do mundo ficcional e os do mundo real, de } \\
\text { forma inteligível ao receptor. }\end{array}$ \\
\hline
\end{tabular}

Fonte: Elaborado pelos autores, 2020.

Figura 5 - Lar é o lugar em que os heróis estão \#connectedtogether

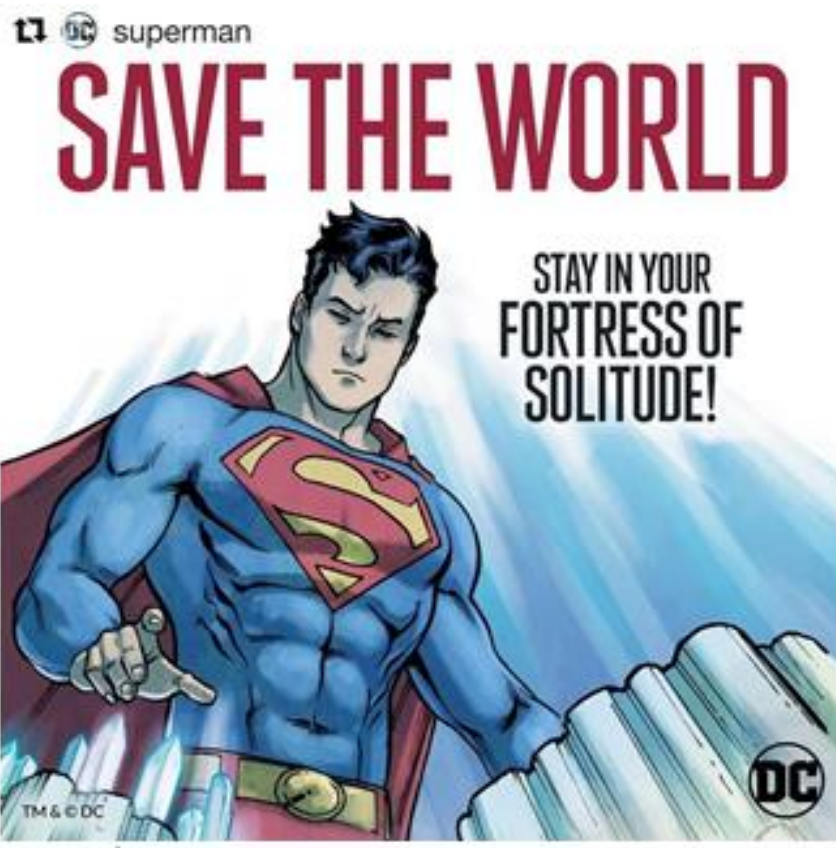

Fonte: Perfil oficial da DC Comics no Instagram ${ }^{6}$

${ }^{6}$ Disponível em https://www.instagram.com/p/B_F30CXD4rg/. Acesso em ago. 2020 
Quadro 4 - Narratologia em lar é o lugar em que os heróis estão \#connectedtogether

\begin{tabular}{|c|c|}
\hline CATEGORIA & ANÁLISE \\
\hline Enredo & $\begin{array}{l}\text { A Fortaleza da Solidão, lar do Super-Homem, é um lugar isolado, que exerce } \\
\text { a função de repouso, segurança e privacidade ao herói, quando assim ele } \\
\text { necessita. Em diversas ocasiões, os lares são para as pessoas um local para } \\
\text { se isolador, quando assim o desejam e podem. }\end{array}$ \\
\hline Personagens & $\begin{array}{l}\text { É inegável que o Super-Homem é o super-herói mais conhecido do mundo. } \\
\text { Como parte da sua mitologia, a Fortaleza da Solidão é o seu quartel general } \\
\text { próprio. Trata-se de um local isolado e justamente por isso, reforça a } \\
\text { necessidade de isolamento que o COVID-19 trouxe para toda a humanidade. }\end{array}$ \\
\hline Noção de Tempo & $\begin{array}{l}\text { Tempo psicológico - não é possível precisar o período exato em que essa } \\
\text { narrativa ocorreu. Atribui-se ao do isolamento imposto pelo COVID-19. }\end{array}$ \\
\hline Noção de Espaço & $\begin{array}{l}\text { A ação transcorre no retrato da Fortaleza da Solidão do Super-Homem } \\
\text { como um ponto isolado, com que o leitor pode se identificar em especial } \\
\text { neste período de isolamento social para manutenção da saúde. }\end{array}$ \\
\hline Narrador & $\begin{array}{l}\text { O Super-Homem exerce a narração da história, ao evocar a existência de um } \\
\text { local como sua Fortaleza da Solidão como seu lar, que propicia o } \\
\text { isolamento, condição crucial para que todos possam melhor se defenderem } \\
\text { do contágio e dos efeitos adversos da pandemia. E este local pode ser o lar } \\
\text { de cada indivíduo, assim como a Fortaleza da Solidão é um lar para o Super- } \\
\text { Homem. }\end{array}$ \\
\hline
\end{tabular}

Fonte: Elaborado pelos autores, 2020.

\section{Turma da Mônica - Maurício de Sousa Produções}

A brasileira Maurício de Sousa Produções produziu conteúdos com os personagens da Turma da Mônica, voltados para ressaltar a importância do combate e da prevenção ao Corona vírus e prestar homenagem a cientistas brasileiras e estrangeiras, cuja pesquisa sobre o vírus ou sua prevenção tem significativa importância, veiculada em perfis do Instagram - https://www.instagram.com/turmadamonica/ - hashtag \#DonasDaRua. Como quebra de um dos maiores paradigmas da nona arte, o personagem Cascão, que sempre exibira pavor de água, adere à campanha da Turma da Mônica contra o Corona vírus, como se vê abaixo: 
Figura 6 - Sem Abraço, Sem Beijinho, Sem Aperto De Mão

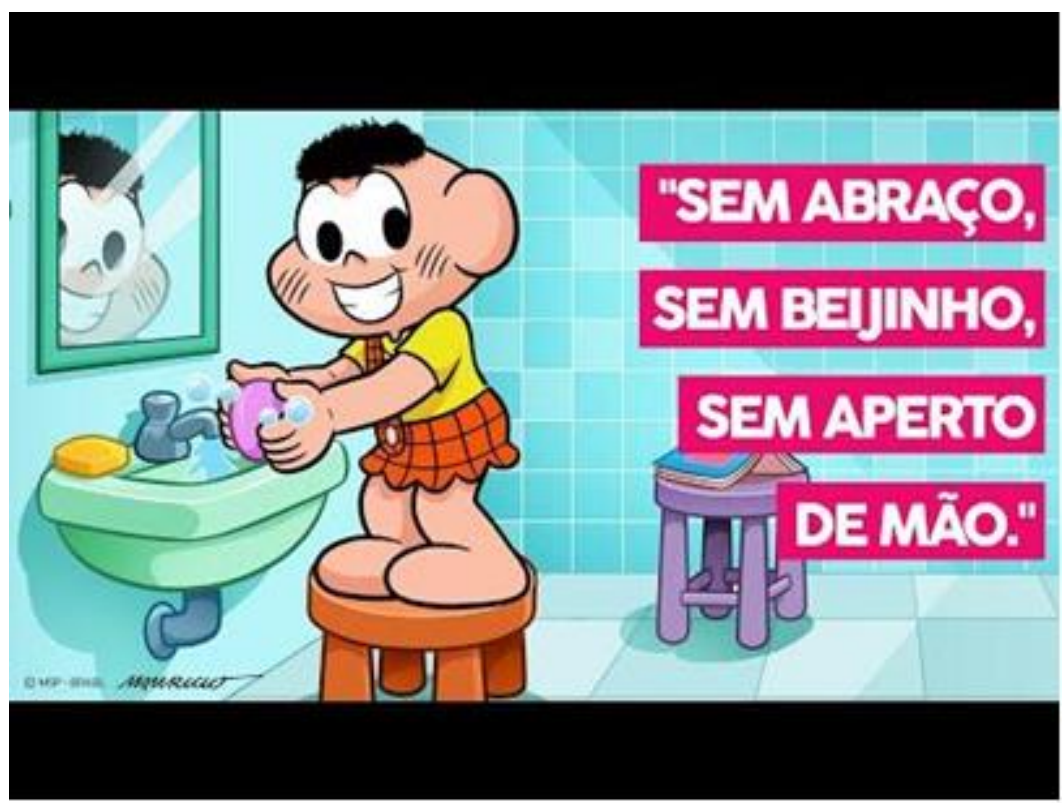

Fonte: Perfil oficial da Turma da Mônica no Instagram7

\section{Quadro 5 - Sem Abraço, Sem Beijinho, Sem Aperto De Mão}

\begin{tabular}{|l|l|}
\hline \multicolumn{1}{|c|}{ CATEGORIA } & \multicolumn{1}{c|}{ ANÁLISE } \\
\hline Enredo & $\begin{array}{l}\text { O personagem Cascão da Turma da Mônica, notadamente conhecido pela sua } \\
\text { aversão à água e aos hábitos de higiene a ela associados, realiza um ato até então } \\
\text { impensável: lava suas mãos com água e sabão. }\end{array}$ \\
\hline Personagens & $\begin{array}{l}\text { O Cascão, sempre retratado como um menino imundo por não se lavar, protagoniza } \\
\text { uma ação irreconhecível diante de seu histórico: lavar as mãos. Mas a mesma é } \\
\text { endossada na medida em que se relaciona com o atual momento de pandemia. O } \\
\text { simples ato de lavar as mãos de forma correta é constantemente abordado pelas } \\
\text { autoridades sanitárias como uma forma de prevenção adequada ao COVID-19. }\end{array}$ \\
\hline Noção de Tempo & $\begin{array}{l}\text { Tempo psicológico - o tempo de se lavar as mãos, bastante associado ao momento } \\
\text { da pandemia e a importância desta ação como profilaxia no combate ao COVID-19. }\end{array}$ \\
\hline Noção de Espaço & $\begin{array}{l}\text { A história se passa em um banheiro, aparentemente de residência, local apropriado } \\
\text { para executar a higiene pessoal, e presente em quase todos os lares do mundo. } \\
\text { Portanto, um espaço de fácil identificação pelo público leitor. }\end{array}$ \\
\hline Narrador & $\begin{array}{l}\text { O Cascão atua como o narrador da história, não apenas por intermediar o enredo e } \\
\text { o público alvo, mas pela referência que proporciona, com o ineditismo e a expressão } \\
\text { de seu ato. Todo aquele familiarizado com o personagem consideraria esta ação } \\
\text { como improcedente, exceto junto à existência do Corona vírus, e que o simples } \\
\text { gesto de se lavar as mãos é uma das medidas de prevenção ao contato. }\end{array}$ \\
\hline
\end{tabular}

Fonte: Elaborado pelo autor, 2020. 
Figura 7 - Ester e Jaqueline \#Asdonasdarua

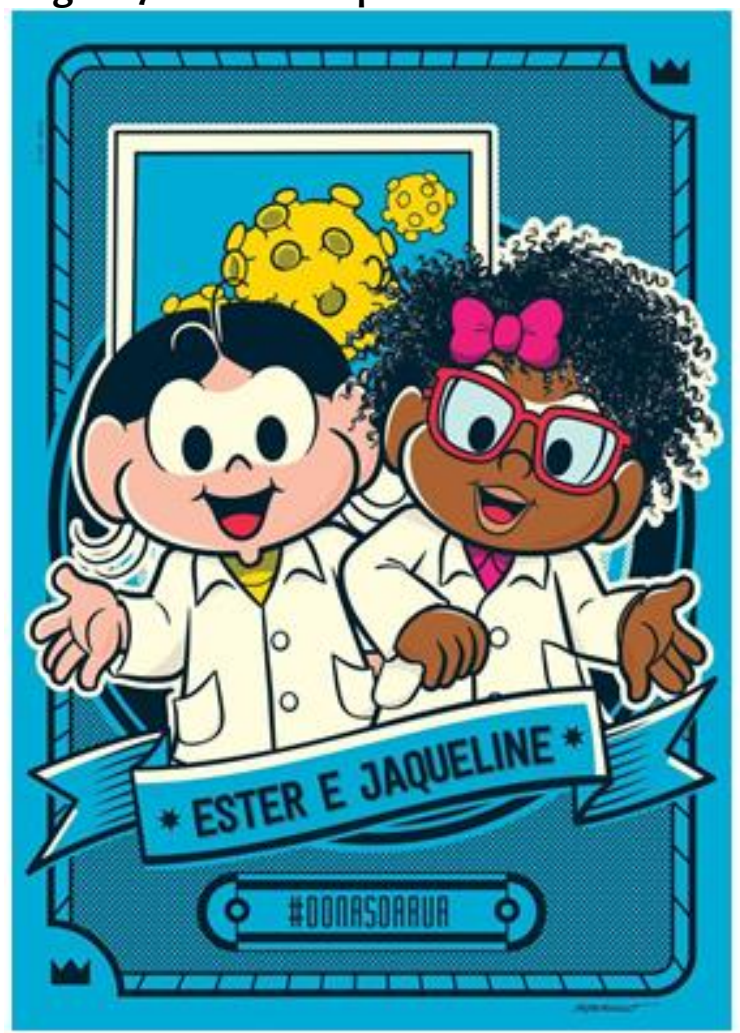

Fonte: Perfil meninas na ciência UFRJ no Instagram ${ }^{8}$

\section{Quadro 6 - Narratologia em Ester e Jaqueline \#Donasdarua}

\begin{tabular}{|c|c|}
\hline CATEGORIA & ANÁLISE \\
\hline Enredo & $\begin{array}{l}\text { As pesquisadoras brasileiras Ester Sabino e Jaqueline Góes de Jesus, lideranças nos } \\
\text { estudos sobre o Corona vírus no país, foram homenageadas pela Maurício de Sousa } \\
\text { Produções. Na imagem destacada, Ester aparece no corpo de Magali e Jaqueline no } \\
\text { corpo de Milena, a primeira protagonista negra da Turma. A homenagem reside no fato } \\
\text { de que ambas as pesquisadoras brasileiras foram as primeiras a decifrar o genoma do } \\
\text { Corona vírus, em menos de } 48 \text { horas após o Ministério da Saúde confirmar o primeiro } \\
\text { caso no Brasil. }\end{array}$ \\
\hline Personagens & Magali e Milena, da Turma da Mônica. \\
\hline Noção de Tempo & $\begin{array}{l}\text { Tempo psicológico - não é possível precisar o período exato em que essa narrativa } \\
\text { ocorreu. Atribui-se ao relativo ao isolamento imposto pelo COVID-19. }\end{array}$ \\
\hline Noção de Espaço & $\begin{array}{l}\text { Não é possível precisar a localidade desta imagem, com base nos elementos fornecidos } \\
\text { pela mesma. }\end{array}$ \\
\hline Narrador & $\begin{array}{l}\text { Magali e Milena foram as personagens deliberadamente escolhidas pela Maurício de } \\
\text { Sousa para representarem as pesquisadoras brasileiras Ester e Jaqueline, pelos } \\
\text { atributos físicos com que são retratadas nas histórias da Turma da Mônica, os quais } \\
\text { prestam, em parte significativa ao de suas contrapartes, homenagem às cientistas do } \\
\text { mundo real. }\end{array}$ \\
\hline
\end{tabular}

Fonte: Elaborado pelos autores, 2020.

${ }^{8}$ Disponível em <https://www.instagram.com/p/Bgb2hxypoa7/> Acesso em ago. 2020. 


\section{CONSIDERAÇÕES FINAIS}

As histórias factuais ou ficcionais que se apresentam no formato de histórias em quadrinhos podem abordar em suas narrativas temas e assuntos pertinentes à realidade cotidiana não apenas de seus leitores frequentes, mas em muitos outros indivíduos, ampliando largamente sua penetração em ocasiões excepcionais, como no caso de uma pandemia mundial. Isso ocorre porque esse produto cultural apresenta em sua criação uma série de ações, fatos, eventos e valores que são praticados fazem parte da vida humana, e estão presentes, em graus e volumes diferenciados no cotidiano das pessoas. Praticamente todas as pessoas conhecem os super-heróis, leram — ou ainda leem mesmo depois de adultos — gibis na infância e tais personagens alegraram e povoaram o imaginário daquela fase da vida.

Iser (1996-1999) acredita que o ser humano demonstra, ao longo de sua existência, não apenas a capacidade, mas também a necessidade intrínseca de se relacionar com aquilo que é ficção. Uma das maneiras dessa relação se processar reside na interação entre o leitor e o texto, podendo também se aplicar à imagem ou vocabulário. As histórias escolhidas neste estudo têm por objetivo narram mensagens referentes à prevenção ao COVID-19, dentre elas destacam-se as relativas às medidas adotadas para se suportar o isolamento social e a passagem do tempo, de forma lúdica e prazerosa e as justas homenagens àqueles que, mesmo diante de uma pandemia instaurada, exercem suas profissões de forma idônea e imprescindível à manutenção da vida.

Ainda que os leitores das histórias em quadrinhos - e mesmo aqueles que não se enquadram propriamente nesta categoria - mas demonstram capacidade de reconhecimento dos personagens retratados nas imagens e histórias compreendem perfeitamente as ações ilustradas pois elas, além de se basearem em práticas humanas, podem inclusive reforçar a compreensão do momento adverso que a humanidade se deparou, o isolamento social devido ao Corona vírus. São cenas que remetem à vida real, ações de prevenção ao contato com o vírus, como lavar as mãos como faz o Cascão, proceder ao isolamento como o Super-Homem, a consciência de que a vida deve prosseguir, mesmo de forma atípica ao padrão social anteriormente adotado, atividades rotineiras como cuidar da própria casa e de seus itens pessoais, o Homem-Aranha cozinhando em casa como aconteceu com quase todas as pessoas em isolamento e em atividades simples de passatempo e recreação, como o quebracabeça montado por Wolverine.

As histórias em quadrinhos, independentemente do país de origem, formato de publicação ou gênero textual a que pertencem, podem também ser consideradas como fontes de informação, quando resgatadas da memória e empregadas para facilitar e potencializar a compreensão singular de um fato, evento ou acontecimento. Certamente esta é a intenção dos quadrinhos analisados no artigo, ao desenvolverem as histórias que trazem ações e fatos relativos ao COVID-19. Tal afirmação se ratifica pelo entendimento de Messias e Grippa (2017, p.7), ao apontarem que "estudos indicam que as histórias em quadrinhos [...] são fontes de informação, servindo como documentos que motivam a circulação de conhecimento". Portanto, seu acesso e leitura podem ser estimulados, na medida em que se reconhece que a ficção é uma instância presente na vida humana, de forma especial quando o leitor pode ser levado a vivenciar uma ou mais experiências através de uma leitura ficcional que, de acordo com Iser (1999), seja capaz de revelar algo sobre nós mesmos.

A narratologia (Gancho, 2002) comprovou ser método de pesquisa adequado junto às histórias em quadrinhos, auxiliando na interpretação de suas imagens e, sobretudo, nas narrativas. Suas categorias de análise aplicadas ao conjunto de quadrinhos 
abordados neste estudo, em especial as formas para a prevenção e ilustrações sobre como os personagens lidam com o isolamento, foram de importância singular para a compreensão do que o leitor pode imprimir ou exprimir sentido, significado e motivações, a partir da leitura dos quadrinhos.

O caminho a ser percorrido pelos estudos da leitura, em particular de formatos e de personagens não tradicionalmente abordados pela academia como as histórias em quadrinhos, ainda é longo. Entretanto, é possível acreditar que alguns dos preconceitos atribuídos a elas vêm gradativamente perdendo força, graças a pesquisas e estudos competentes provenientes de várias áreas do conhecimento, inclusive da Ciência da Informação. Tratam-se de produtos culturais e fontes de informação, capazes de produzir respostas junto a seus leitores e podem auxiliar na compreensão de hábitos e práticas de pessoas, como o presente caso das histórias examinadas sobre o COVID-19. A experiência de pesquisas na área tem rendido bons frutos, demonstrando a relevância social das histórias em quadrinhos, a viabilidade dos estudos e o consequente encorajamento para a sua continuação.

\section{REFERÊNCIAS}

ARAÚJO, Nelma Camêlo; FACHIN, Juliana. Evolução das fontes de informação. Biblos, Carreiros, v. 29, n. 1, p. 81-96. 2015. Disponível em:

https://periodicos.furg.br/biblos/article/view/5463/3570. Acesso em: 09 nov. 2020.

BARBIERI, Daniele. Los linguajes del cómic. Barcelona: Paidós, 1998.

BARBOSA, Márcio Ferreira. Experiência e narrativa. Salvador: Edufba, 2003.

CAPURRO, Rafael; HJØRLAND, Birger. O Conceito de informação. Perspectivas em Ciência da Informação, Belo Horizonte, v. 12, n. 1, p. 148-207, 2007. Disponível em: http://portaldeperiodicos.eci.ufmg.br/index.php/pci/article/view/54/47. Acesso em: 13 maio 2020.

CHARTIER, Roger. Cultura escrita, literatura e história: conversas de Roger Chartier com Carlos Aguirre Anaya, Jesús Anaya Rosique, Daniel Goldin e Antonio Saborit. Porto Alegre: Artmed, 2001.

DUMONT, Lígia Maria Moreira. Contexto, leitura e subjetividade. Transinformação, Campinas, v.13, n.1, p. 43- 47, jan. / jun. 2001. Disponível em:

https://www.scielo.br/pdf/tinf/v13n1/03.pdf. Acesso em: 08 abr. 2020.

DUMONT, Lígia Maria Moreira. Leitura e competência informacional: interseções e interlocuções. In: ENCONTRO DA ASSOCIAÇÃO NACIONAL DE PESQUISA E PÓSGRADUAÇÃO EM CIÊNCIA DA INFORMAÇÃO - ENANCIB, 18., 2017, Marília, SP. Anais eletrônicos... Marília; UNESP. 2017. Disponível em:

http://enancib.marilia.unesp.br/index.php/XVIII_ENANCIB/

ENANCIB/paper/viewFile/569/690. Acesso em: 29 jun. 2020.

GANCHO, Cândida Vilaes. Como analisar narrativas. São Paulo: Ática, 2002.

GIL, Antônio Carlos. Como elaborar projetos de pesquisa. 4. ed. São Paulo : Atlas, 2002. 
ISER, Wolfgang. $O$ ato da leitura: uma teoria do efeito estético. São Paulo : Editora 34, 1999. v. 2.

MARTELETO, Regina Maria. Informação da sociedade na sociedade da informação. Perspectivas em Ciência da Informação, Belo Horizonte, n. esp., p. 4-7, 2003. Disponível em: http://portaldeperiodicos.eci.ufmg.br/index.php/pci/article/ view/647/434. Acesso em: 10 maio 2020.

MESSIAS, Carolina Ito; GRIPPA, Giulia. Histórias em quadrinhos na internet como fontes de informação. In: ENCONTRO NACIONAL DE PESQUISA EM CIÊNCIA DA INFORMAÇÃO - ENANCIB, 18., 2017, Marília. Anais eletrônicos... Marília: UNESP, 2017. Disponível em: http://enancib.marilia.unesp.br/index.php/XVIIIENANCIB/ENANCIB/ paper/viewFile/291/660. Acesso em: 09 nov. 2017.

MINAYO, Maria Cecília de Souza. O desafio da pesquisa social. In: DESLANDES, Suely Ferreira; GOMES, Romeu; MINAYO, Maria Cecília de Souza (Orgs.). Pesquisa social: teoria, método e criatividade. Petrópolis: Vozes, 2011. p. 9-29.

OLIVEIRA, Maria Jaciara de Azeredo. As histórias em quadrinhos como fonte de informação: uma leitura de fábulas no âmbito da Ciência da Informação. 2014. Dissertação (Mestrado em Ciência da Informação) - Universidade Federal Fluminense. Niterói, RJ, 2014. Disponível em: http://www.ci.uff.br/ppgci/arquivos/Dissert/2014/ DISSERTA\%C3\%87\%C3\%83O_MARIA\%20JACIARA\%20DE\%20AZEREDO\%20OLIVEIRA.pdf. Acesso em: 10 nov. 2020.

RAMOS, Rubem Borges Teixeira. Com grandes poderes, vêm grandes responsabilidades: um estudo etnometodológico sobre o leitor e a leitura de histórias em quadrinhos de super-heróis da Marvel e da DC Comics. 252 f. Tese (Doutorado em Ciência da Informação)- Escola de Ciência da Informação. Universidade Federal de Minas Gerais, Belo Horizonte, Brasil, 2017. Disponível em:

http://www.bibliotecadigital.ufmg.br/dspace/bitstream/handle/1843/BUBD-AXWMUC/ tese_doutorado_vers_o_para_encaderna_o__vers_o_?nal.pdf?sequence $=1$. Acesso em: 10 nov. 2020.

VERGUEIRO, Waldomiro de Castro Santos. Histórias em quadrinhos. In: CAMPELLO, Bernadete Santos; CALDEIRA, Paulo da Terra; MACEDO, Vera Amália Amarante (Orgs.). Formas e expressões do conhecimento: introdução às formas de informação. Belo Horizonte: Escola de Biblioteconomia da UFMG, 1998. p. 115-149.

VERGUEIRO, Waldomiro de Castro Santos. Pesquisa acadêmica em histórias em quadrinhos. São Paulo: Criativo, 2017. 